Trans-epithelial transport of the betalain pigments indicaxanthin and betanin across

Caco-2 cell monolayers and influence of food matrix

L. Tesoriere, C. Gentile, F. Angileri, A. Attanzio, M. Tutone, M. Allegra \& M. A. Livrea

European Journal of Nutrition

ISSN 1436-6207

Eur J Nutr

DOI 10.1007/s00394-012-0414-5

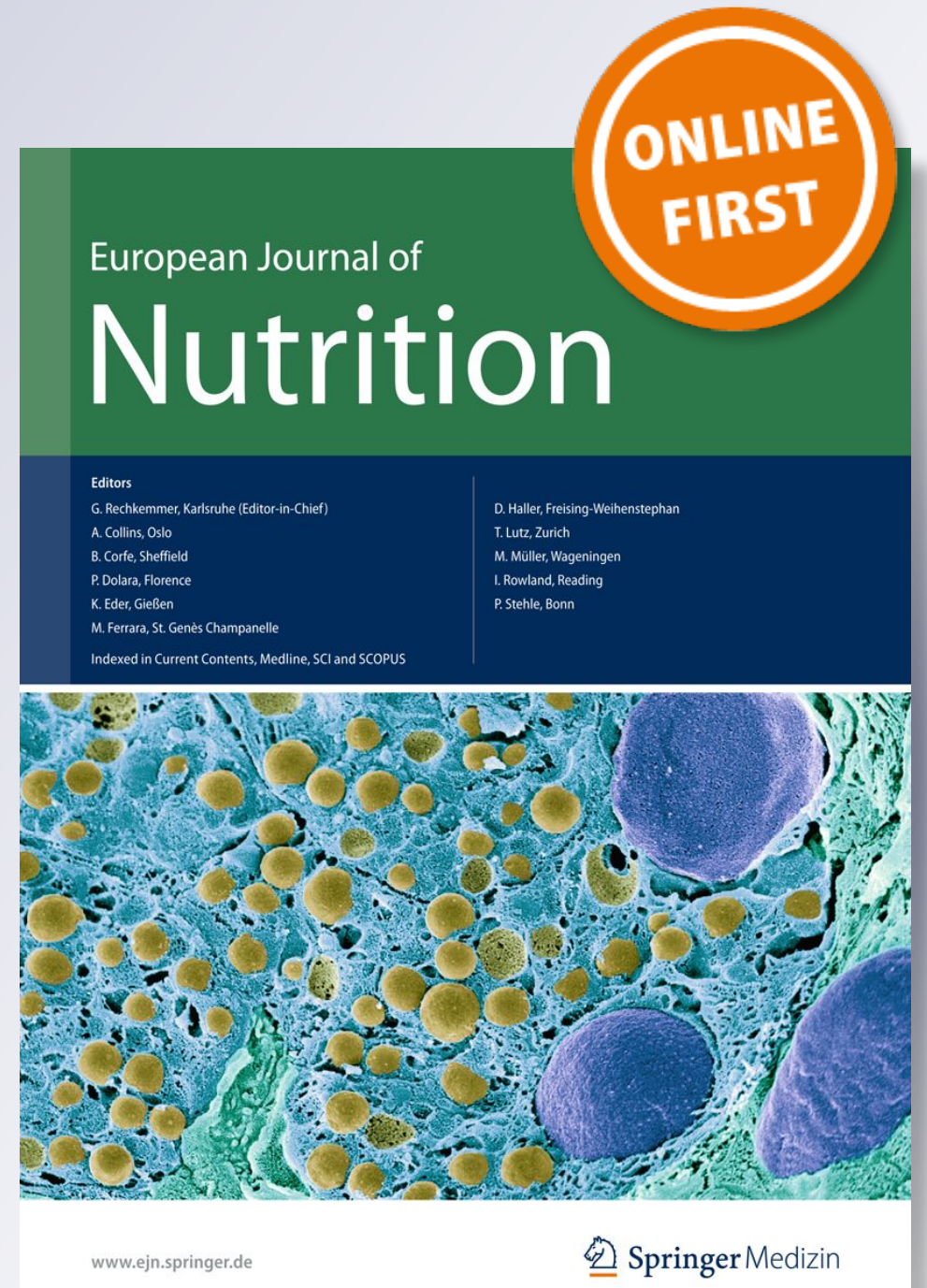

Springer 
Your article is protected by copyright and all rights are held exclusively by SpringerVerlag. This e-offprint is for personal use only and shall not be self-archived in electronic repositories. If you wish to self-archive your work, please use the accepted author's version for posting to your own website or your institution's repository. You may further deposit the accepted author's version on a funder's repository at a funder's request, provided it is not made publicly available until 12 months after publication. 


\title{
Trans-epithelial transport of the betalain pigments indicaxanthin and betanin across Caco-2 cell monolayers and influence of food matrix
}

\author{
L. Tesoriere $\cdot$ C. Gentile $\cdot$ F. Angileri $\cdot$ \\ A. Attanzio $\cdot$ M. Tutone $\cdot$ M. Allegra . \\ M. A. Livrea
}

Received: 23 January 2012/ Accepted: 27 June 2012

(C) Springer-Verlag 2012

\begin{abstract}
Purpose This study investigated the absorption mechanism of the phytochemicals indicaxanthin and betanin and the influence of their food matrix (cactus pear and red beet) on the intestinal transport.

Methods Trans-epithelial transport of dietary-consistent amounts of indicaxanthin and betanin in Caco-2 cell monolayers seeded on Transwell ${ }^{R}$ inserts was measured in apical to basolateral (AP-BL) and basolateral to apical (BL-AP) direction, under an inwardly directed $\mathrm{pH}$ gradient (pH 6.0/7.4, AP/BL) mimicking luminal and serosal sides of human intestinal epithelium. The effect of inhibitors of membrane transporters on the absorption was also evaluated. Contribution of the paracellular route was investigated after EDTA treatment of the cell monolayer. In vitro digestion of betalainic food was performed to provide a post-intestinal fraction containing bioaccessible pigments. Results Apparent permeability coefficients $\left(P_{\text {app }}\right)$ in the absorptive direction were $(4.4 \pm 0.4) \times 10^{-6}$ and $(3.2 \pm 0.3) \times 10^{-6} \mathrm{~cm} \mathrm{~s}^{-1}$ for indicaxanthin and betanin, respectively. Transport of indicaxanthin was non-polarized, linear as a function of time and concentration, and unaffected by inhibitors of membrane transporters. Betanin exhibited significantly different bidirectional $P_{\text {app }}$ values and non-linear efflux kinetics. The concentration-dependent betanin efflux was described by a kinetic model including one non-saturable $\left(K_{d}=0.042 \mu \mathrm{L} \mathrm{cm}^{-2} \min ^{-1}\right)$ and one saturable component identified as the apical
\end{abstract}

L. Tesoriere $\cdot$ C. Gentile $\cdot$ F. Angileri · A. Attanzio

M. Tutone $\cdot$ M. Allegra $\cdot$ M. A. Livrea $(\square)$

Dipartimento di Scienze e Tecnologie Molecolari e

Biomolecolari (STEMBIO), Università di Palermo,

Via Michele Cipolla 74, 90123 Palermo, Italy

e-mail: maria.livrea@unipa.it multidrug resistance-associated protein 2 (MRP2;

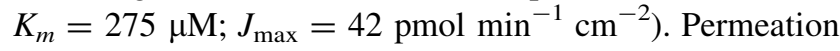
of both betalains increased remarkably after EDTA treatment of the cell monolayer. Neither indicaxanthin nor betanin underwent metabolic transformation. Food matrix did not affect trans-epithelial transfer of indicaxanthin, but reduced the absorption rate of betanin, red beet more than cactus pear.

Conclusions Dietary indicaxanthin and betanin can substantially be absorbed through paracellular junctions of intestinal epithelial cells. Additional trans-membrane permeation can be considered for betanin, whose absorption is limited by a MRP2-mediated efflux and negatively affected by its food matrix. Present findings are consistent with the quite higher bioavailability of indicaxanthin over betanin established in humans.

Keywords Betalains - Intestinal absorption - Caco-2 cells . Betalainic food · Indicaxanthin · Betanin

\section{Introduction}

Health benefits of dietary phytochemicals have been suggested in recent years. Among thousands of different compounds, phenolics, terpenoids, and sulfur-containing compounds have been considered because of reducing power and potential to affect redox-modulated cellular processes [1-3]. Betalains, which occur in a number of vegetables of the Cariophyllalae order, with cactus pear (Opuntia genus) fruits and red beet (Beta vulgaris) as the more representative dietary sources, are nitrogen-containing compounds, the structure of which comes from a tyrosine derivative known as betalamic acid. Depending on the components bonded to the main structure, violet-red 
betacyanins or orange-yellow betaxanthins arise, the former when the component is 3,4-dihydroxy-phenylalanine (DOPA), which may be or may be not glycosylated, and the latter if the conjugation partners are amino acids or derived amines $[4,5]$. The potential use of this class of molecules as natural dyes has widely been explored in the past, and experimental evidence has been provided about safety and factors affecting their stability under a variety of conditions [6, 7]. More recently, a number of bioactivities have emerged from in vitro studies in solution and in cell cultures. In particular, indicaxanthin and betanin (Fig. 1), the adducts of betalamic acid with proline and cycloDOPA 5-O- $\beta$ glucoside, respectively, exhibited antioxidant activity in biological lipid environments from human lowdensity lipoproteins to membranes and whole cells [8-12], were able to modulate redox-mediated signal transduction pathways involved in inflammation in cultured endothelium [13], and showed antiproliferative effects in human tumor cell lines [14-16].

The health benefits of dietary phytochemicals cannot easily be deduced from in vitro studies, one main reason being that phytochemicals are processed as xenobiotics, that is, they may be or may be not absorbed to a suitable amount, transported in blood and distributed to tissues, metabolized and excreted. Human studies after the ingestion of dietary amounts of cactus pear fruit [17] or red beet juice [18, 19] indicated that indicaxanthin and betanin reach plasma concentrations of a micromolar order, which is quite higher than other phytochemicals such as polyphenols [20, 21]. In other studies [22], by a simulated gastro-intestinal digestion, we were able to demonstrate that digestive stability and additional factors relevant to the solubilization from food matrix and style of food processing influence the fraction of soluble betalains in the post-intestinal digesta potentially available for trans-epithelial transfer. Other factors that may concur to betalain bioavailability, including intestinal metabolism and mechanism of trans-epithelial transport, as well as interference of the food matrix on the
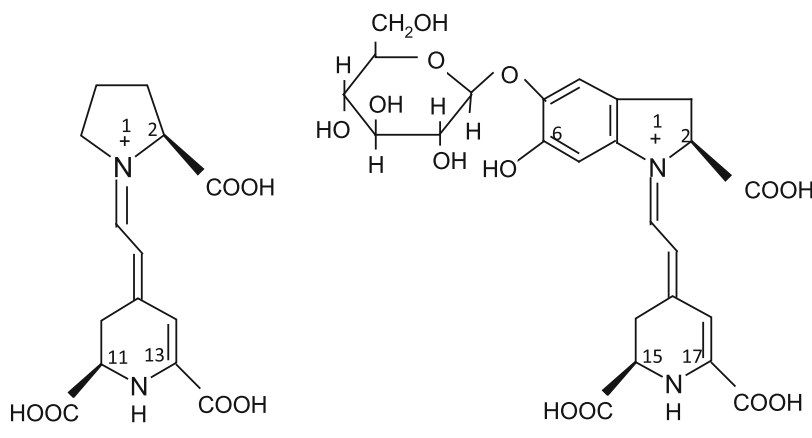

Indicaxanthin absorptive process, are still unknown. In this study, we investigate intestinal permeation of indicaxanthin and betanin using Caco- 2 cell monolayers seeded on Transwell ${ }^{\circledR}$ insert, a well-established model of the intestinal barrier. Originating from a human colorectal carcinoma, these cells spontaneously differentiate into polarized monolayers that exhibit morphological and functional characteristics of the intestinal absorptive epithelium, including intercellular tight junctions and apical microvilli, carriers for nutrient as well as efflux proteins, and a number of phase-2 enzymes required to xenobiotic disposition [23, 24]. In addition, since food matrix can affect absorption, the trans-epithelial permeation of betalains from various betalainic food submitted to a simulated gastro-intestinal digestion was compared with that of the pure compounds.

\section{Materials and methods}

Unless stated otherwise, all reagents and materials were from Sigma Chemical Co. (St Louis, MO, USA) and solvents were of the highest purity or HPLC grade.

\section{Betalain pigments}

Betanin and indicaxanthin were isolated from cactus pear fruits as previously reported [25] and then purified according to Stintzing et al. [26]. The betalains were spectrophotometrically quantified using molar absorbance of 65,000 at $536 \mathrm{~nm}$ and 42,800 at $482 \mathrm{~nm}$ for betanin and indicaxanthin, respectively.

\section{Physicochemical properties}

Molecular descriptors of the betalains such as ClogP, ClogD were computed by Qikprop 3.1 predict program (Schrodinger, LLC, New York, NY, USA). The non-polar surface area (NPSA) was obtained as the difference between the molecular surface area (MSA) and polar surface area (PSA), calculated by CODESSA PRO software [27]. $\mathrm{p} K_{\mathrm{a}}$ values of indicaxanthin were obtained by two different approaches, that is, the semi-empirical partial charge related and the Hammet and Taft linear free-energy relationships. Semi-empirical calculations were made by means of Marvin Sketch 5.0.6.1 prediction program (ChemAxon, Budapest, Hungary), based on the calculation of Mulliken partial charge of atoms in the molecule. The Hammet and Taft linear free-energy relationships were calculated by Epik 1.6 software (Schrödinger, LLC, New York, NY, USA), which adopts the combination of Hammet and Taf methods in conjunction with ionization and tautomerization tools. The $\mathrm{p} K_{\mathrm{a}}$ values of betanin were obtained from the literature [28].

Fig. 1 Molecular structure of indicaxanthin and betanin 


\section{Cell culture}

Caco-2 cells, obtained from the American Type Culture Collection (Rockville, MD, USA), were cultured in Dulbecco's modified Eagle medium (DMEM; Gibco Life Technologies, Grand Island, NY, USA) supplemented with $10 \%$ fetal bovine serum (Gibco Life Technologies), $1 \%$ non-essential amino acids, $10 \mathrm{mM}$ HEPES, 50 units $/ \mathrm{mL}$ penicillin, $50 \mu \mathrm{g} / \mathrm{mL}$ streptomycin, and $100 \mu \mathrm{g} / \mathrm{mL}$ gentamicin and were maintained at $37{ }^{\circ} \mathrm{C}$ in $5 \% \mathrm{CO}_{2}$ and $95 \%$ humidity. Medium was changed 2-3 times per week. Caco2 cells were used between passages 27 and 31 . The cells were monitored by phase contrast microscopy, and fluorescent staining of DNA by Hoechst 33,258 (Thermo Fisher Scientific, Rockford, IL, USA) was used once a month to rule out mycoplasma contamination.

In vitro simulated digestion and preparation of the bioaccessible fraction from betalainic food

Fresh cactus pear fruits (O. ficus indica L. Mill.) from yellow and red Sicilian cultivars and red beet roots (B. Vulgaris L. ssp Vulgaris) from Tuscany (Italy) cultivations were obtained from a local market. Red beet juice (Biotta AG, CH-8274, Tagewiler, Switzerland) was purchased in a healthy food store. Cactus pear fruit juice was prepared after brief homogenization of the pulp in a kitchen-type blender and filtration through a colander $(0.2 \mathrm{~mm}$ mesh size). Aliquots (20 g of each food preparation) was chewed 10 times by a single investigator and subsequently expelled in a tared beaker. The post-oral material was briefly homogenized in Hanks' balanced salt solution, pH 7.4 (HBSS, 1:2, w:v) for $2 \mathrm{~min}$ in a laboratory blender (Waring, New Hartford, CT), acidified at pH 2.0 with $\mathrm{HCl}$, and $8 \mathrm{mg} / \mathrm{mL}$ porcine pepsin (3,200-4,500 units/ $\mathrm{mg}$ ) was added. After incubation in a shaking (100 rpm) water bath (type M 428-BD, Instruments s.r.l., Bernareggio, $\mathrm{Mi}$, Italy) at $37^{\circ} \mathrm{C}$, for $2 \mathrm{~h}$ to simulate the gastric phase, the $\mathrm{pH}$ of the sample was immediately increased to 7.4 with $0.5 \mathrm{M} \mathrm{NaHCO}_{3}$. The small intestinal phase of digestion was started after the addition of $2.4 \mathrm{mg} / \mathrm{mL}$ porcine bile extract and $0.4 \mathrm{mg} / \mathrm{mL}$ pancreatin. After incubation in the shaking water bath as above, for $2 \mathrm{~h}$ at $37{ }^{\circ} \mathrm{C}$, the post-intestinal digest was centrifuged at $167,000 \mathrm{~g}$, for $35 \mathrm{~min}$ at $4{ }^{\circ} \mathrm{C}$ in a Beckman Optima TLX ultracentrifuge, equipped with an MLA-55 rotor (Beckman Instruments, Inc., Palo Alto, CA, USA), to separate the aqueous bioaccessible fraction (BF) from particulate material. Digestive enzymes were removed by ultracentrifugation through YM-10 membranes, and the betalain content of BF was measured by HPLC. Food BF was stored at $-80{ }^{\circ} \mathrm{C}$ until use.

Cytotoxicity of the BFs on Caco- 2 cells was checked in pilot studies. Caco- 2 cells were seeded at $5 \times 10^{5}$ cells well in a six-well flat-bottom plate, and the medium was changed three times a week. After 15 days from confluence, differentiated monolayers were washed three times with HBSS, and then $2 \mathrm{~mL}$ of food BF was added. The BFs were filtered through a Millex HV $0.2 \mu \mathrm{m}$ filter (Millipore, Billerica, MA, USA) immediately before the use. After a 90-min incubation, cells were washed and $50 \mu \mathrm{L}$ HBSS containing $5 \mathrm{mg} / \mathrm{mL}$ MTT was added. The medium was discarded after a 4-h incubation at $37{ }^{\circ} \mathrm{C}$, and formazan blue formed in the cells was dissolved in DMSO. The absorbance at $540 \mathrm{~nm}$ of MTT formazan of untreated cells was taken as $100 \%$ viability. In addition, viability of the cells after the treatment was determined by trypan blue exclusion and microscopy examination. Neither treatment caused cell toxicity.

\section{Trans-epithelial transport}

Transport experiments were carried out using Transwell ${ }^{\mathrm{R}}$ inserts (polycarbonate membrane, $0.4 \mu \mathrm{m}$ pore size, $24 \mathrm{~mm}$ diameter, Corning Inc., Corning, NY, USA). Inserts were placed in 6-well plates. Caco-2 cells were seeded at $5 \times 10^{4}$ cells per $\mathrm{cm}^{2}$ on the membrane insert with $1.5 \mathrm{~mL}$ of medium in the apical/luminal side (AP) and $2.5 \mathrm{~mL}$ of medium in the basolateral/serosal side (BL). Cells reached confluence within 5 days post-seeding. Culture medium was changed three times a week. On day 15 after reaching confluence, the DMEM was removed and the cells were rinsed three times with HBSS. The integrity of Caco- 2 cell monolayers was evaluated by measuring the trans-epithelial electric resistance (TEER), according to Hidalgo et al. [29]. TEER values across the cell monolayers were measured using a Millicell-ERS voltohmeter (Millipore Corp., Bedford, MA). Only monolayers with TEER $>300 \Omega / \mathrm{cm}^{2}$ were utilized. After washing of the cells with HBSS as reported above, $100 \mu \mathrm{M}$ indicaxanthin, betanin or food $\mathrm{BF}$ in HBSS was added to the donor compartment and HBSS to the acceptor one. HBSS in the apical compartment was buffered at pH 6.0 with $20 \mathrm{mM} 2$-( $N$-morpholine) ethanesulfonic acid (MES). When necessary, HBSS of various either inhibitors (pravastatin, $5 \mathrm{mM}$; verapamil, $5 \mathrm{mM}$; indomethacin, $10 \mathrm{mM}$ ) or substrates (ferulic acid, $10 \mathrm{mM}$; acetic acid, $5 \mathrm{mM}$; valproic acid, $10 \mathrm{mM}$; glucose $10 \mathrm{mM}$ ) of membrane transporters was added in the AP side. Concentration-dependent trans-epithelial transport of either indicaxanthin or betanin was measured by varying the betalain concentrations between $100 \mu \mathrm{M}$ and $2 \mathrm{mM}$ under all other conditions unaltered. Cultures were incubated $\left(37{ }^{\circ} \mathrm{C}, 5 \% \mathrm{CO}_{2}\right)$ and the acceptor medium was taken at 15-min time-intervals between 0 and 90 min and replaced with fresh HBSS. The acceptor medium was centrifuged at $1,000 \mathrm{~g}$ for $10 \mathrm{~min}$ at $4{ }^{\circ} \mathrm{C}$ and submitted to HPLC analysis of betalains. In parallel experiments, the flux of marker 
compounds, phenolsulfonaphtalein (phenol red, $5 \mathrm{mM}$ ) and testosterone $(100 \mu \mathrm{M})$, was evaluated by spectrophotometric and HPLC analysis, respectively [30]. Thermal stability of betalains ( $100 \mu \mathrm{M}$ to $2 \mathrm{mM})$ under the conditions of the experiments was checked in the absence of cells. No significant loss of both pigments was observed after 90-min incubation at $37{ }^{\circ} \mathrm{C}$.

The effect of either purified betalains or food BF on the barrier integrity of Caco- 2 cell monolayers was assessed by checking the TEER values at the end of each transport experiment. In addition, the transfer of phenol red from the AP-to-BL compartment was also measured. Under the conditions applied, treatment with either betalains or BF did not significantly modify the monolayer resistance or barrier integrity.

The apparent permeability coefficients $\left(P_{\text {app }}\right)$ were calculated according to the equation

$P_{\text {app }}=\frac{V}{A C_{o}} \frac{\mathrm{d} C}{\mathrm{~d} t} \mathrm{~cm} \mathrm{~s}^{-1}$

where $V=$ the volume of solution in the receiving compartment, $A=$ the membrane surface area $\left(4.71 \mathrm{~cm}^{2}\right)$, $C_{o}=$ the initial concentration in the donor compartment, and $\mathrm{d} C / \mathrm{d} t=$ the steady-state flux across the monolayer calculated as the slope of the curve betalain concentration in the receiving compartment versus time [31].

The mass balance, calculated as the percentage of the original pigment mass accounted for at the end of the transepithelial transport experiments, was assessed by evaluating the compound recovered in the donor and receiving chambers, and associated with cells. To this end, the cell monolayer was washed three times with $2 \mathrm{~mL}$ of HBSS containing $5 \mathrm{mmol} / \mathrm{L}$ sodium taurocholate, to remove the pigment adhered to cell surface. Rinsed cells were scraped in methanol, and each well was washed three times with the same solvent. Cells with washing solvent were immediately extracted, sonicated in ice bath for $5 \mathrm{~min}$, and centrifuged at 2,000 $\mathrm{g}$ for $5 \mathrm{~min}$. Methanol supernatant was collected, and the cells were re-suspended in methanol and extracted again as above. The methanol extracts were gathered and reconstituted in suitable solvent for HPLC analysis of betalains.

Kinetic parameters for the efflux of betanin were obtained by fitting the data to a model incorporating saturable and non-saturable components, according to Eq. 2 (Gepasi software package, 3.30):

$J=\frac{J_{\max } C}{K_{m}+C}+K_{d} C$ pmol $\min ^{-1} \mathrm{~cm}^{-2}$

where $J$ is the flux normalized to unit surface area, $J_{\max }$ is the maximum efflux rate, $K_{m}$ is the kinetic constant for saturable transport, $K_{d}$ is the kinetic constant for nonsaturable transport, and $C$ is the betanin concentration.
Transport after alteration in the tight junction barrier

A $10 \mu \mathrm{M}$ EDTA solution was prepared using PBS solution without $\mathrm{Ca}^{2+} / \mathrm{Mg}^{2+}$ and applied to the apical and basolateral sides of Caco- 2 cell monolayers for $5 \mathrm{~min}$ at $37^{\circ} \mathrm{C}$ [32]. After the solution was removed, cells were washed three times with the PBS without $\mathrm{Ca}^{2+} / \mathrm{Mg}^{2+}$, before adding betalains $(100 \mu \mathrm{M})$, phenol red $(5 \mathrm{mM})$ or testosterone $(100 \mu \mathrm{M})$, at the apical compartment, under $\mathrm{pH}$ gradient conditions ( $\mathrm{pH}$ 6.0/7.4; $\mathrm{AP} / \mathrm{BL}$ ).

HPLC analysis of betalains

HPLC measurements of betalain pigments were performed as reported [25] using a RP-18e Performance column $(100 \times 4.6 \mathrm{~mm}$; Merck, Darmstadt, Germany), equipped with RP-18e Chromolith guard cartridge $(5 \times 4.6 \mathrm{~mm}$, Merck), eluted with a 20-min linear gradient elution from solvent A (1\% acetic acid in water) to $20 \%$ solvent B ( $1 \%$ acetic acid in acetonitrile), at a flow rate of $1 \mathrm{~mL} / \mathrm{min}$. Spectrophotometric detection of indicaxanthin (Rt $9.3 \mathrm{~min}$ ) or betanin (Rt $12.5 \mathrm{~min}$ ) was at $482 \mathrm{~nm}$ or $536 \mathrm{~nm}$, respectively. Quantitation was by reference to curves constructed with 1-100 ng of the purified compounds, and by relating the amount of compound under analysis to the peak area.

\section{Statistical analysis of data}

All data are expressed as mean $\pm \mathrm{SD}$. Three independent observations were made for each experiment. All experiments have been replicated two to three times, to have $6<n<9$. Statistical difference was calculated using unpaired $t$ test. Significance was accepted if the null hypothesis was rejected at the $p<0.05$ level. Calculations and graphs were obtained by Instat-3 statistical software (GraphPad Software Inc., San Diego, CA).

\section{Results}

Physicochemical parameters

Physicochemical parameters and ionization constants calculated for indicaxanthin and betanin are reported in Table 1. Indicaxanthin and betanin are cationized molecules, with a positive charge localized in proximity of the N1 nitrogen (Fig. 1). Both molecules possess a number of ionizable carboxyl groups, with $\mathrm{p} K_{\mathrm{a}}$ between 2.0 and 5.4 from our calculations and literature data. In addition, betanin bears a phenol hydroxyl at the cyclo-Dopa, the $\mathrm{p} K_{\mathrm{a}}$ of which has been reported more acidic than expected [28]. In accordance with the measurements, indicaxanthin 
Table 1 Physicochemical parameters of indicaxanthin and betanin

\begin{tabular}{lllllll}
\hline & MW & $\log \mathrm{P}^{\mathrm{a}}$ & $\log \mathrm{D}^{\mathrm{b}}$ & $\mathrm{PSA}\left(\AA^{2}\right)$ & NPSA $\left(\AA^{2}\right)$ & $\frac{\mathrm{p} K_{\mathrm{a}}}{(\mathrm{COOH})^{\mathrm{c}}}$ \\
\hline Indicaxanthin & 309 & 0.362 & -7.25 & 126.92 & 161.11 & $5.0_{(2)} ; 3.7_{(11)} ; 2.6_{(13)}{ }^{\mathrm{d}}$ \\
Betanin & 551 & -1.767 & -15.63 & 246.53 & 229.26 & $<3.4_{(2)} ; 3.4_{(15)} ; 3.4_{(17)}{ }^{\mathrm{e}}<7.4_{(6)}{ }^{\mathrm{e}}$ \\
\hline
\end{tabular}

The molecular surface is described by the polar surface area (PSA) and the non-polar surface area (NPSA)

${ }^{a}$ Octanol/water partition coefficient

b Octanol/buffer pH 6.0 partition coefficient

${ }^{c} \mathrm{C}$ atom in bracket

d Theoretically calculated $\mathrm{p} K_{\mathrm{a}}$ values (see "Materials and methods")

e $K_{\mathrm{a}}$ values from Ref [28]

mainly exists as a bis-anion at both $\mathrm{pH} 6.0$ and 7.4 , whereas betanin must shift toward a tris-anion around $\mathrm{pH} 7.0$ $[18,28]$.

Trans-epithelial transport of pure betalains

The bidirectional trans-epithelial transport of indicaxanthin and betanin across Caco-2 cell monolayers was investigated under a $\mathrm{pH}$ gradient (6.0/7.4; AP/BL). Functional characteristics of the monolayer were preliminarily checked using phenol red and testosterone as markers for paracellular and trans-cellular permeation, respectively. The values of $P_{\text {app }}$ (AP-to-BL) calculated for these compounds were $0.28 \pm 0.01 \times 10^{-6} \mathrm{~cm} \mathrm{~s}^{-1}$ and $30.1 \pm$ $0.6 \times 10^{-6} \mathrm{~cm} \mathrm{~s}^{-1}$, respectively. Unless specified, transport experiments were done with $100 \mu \mathrm{M}$ of either betalains and the amount of pigment in the receiving compartment was monitored at 15-min time-intervals for $90 \mathrm{~min}$, under initial rate conditions.

The $P_{\text {app }}$ measured for indicaxanthin across the Caco-2 cell monolayer in the absorptive AP-to-BL direction $\left(4.2 \pm 0.4 \times 10^{-6} \mathrm{~cm} \mathrm{~s}^{-1}\right)$ was comparable with that measured in the secretive BL-to-AP direction $(4.4 \pm 0.4 \times$ $10^{-6} \mathrm{~cm} \mathrm{~s}^{-1}$, Fig. 2), indicating a non-polarized transport. In contrast, the calculated $P_{\text {app }}$ of betanin was significantly higher in the absorptive AP-to-BL direction $(3.2 \pm 0.33 \times$ $\left.10^{-6} \mathrm{~cm} \mathrm{~s}^{-1}\right)$ than in the efflux direction $(2.5 \pm$ $0.23 \times 10^{-6} \mathrm{~cm} \mathrm{~s}^{-1}$, Fig. 2). Due to the $-\mathrm{OH}$ phenol group, the $\mathrm{p} K_{\mathrm{a}}$ value of which is near to the $\mathrm{pH}$ in the donor BL compartment, variation in the ratio between bis-anion and tris-anion species in favor of the latter could limit the efflux of betanin, resulting in an asymmetric flux of the phytochemical.

HPLC measurements of the medium in the apical and in basolateral chambers were done to evaluate the mass balance of either indicaxanthin or betanin at the end of each experiment. Peaks relevant to the parent compounds provided evidence of a complete mass balance of both betalains, on the basis of the sum of the cumulative amounts

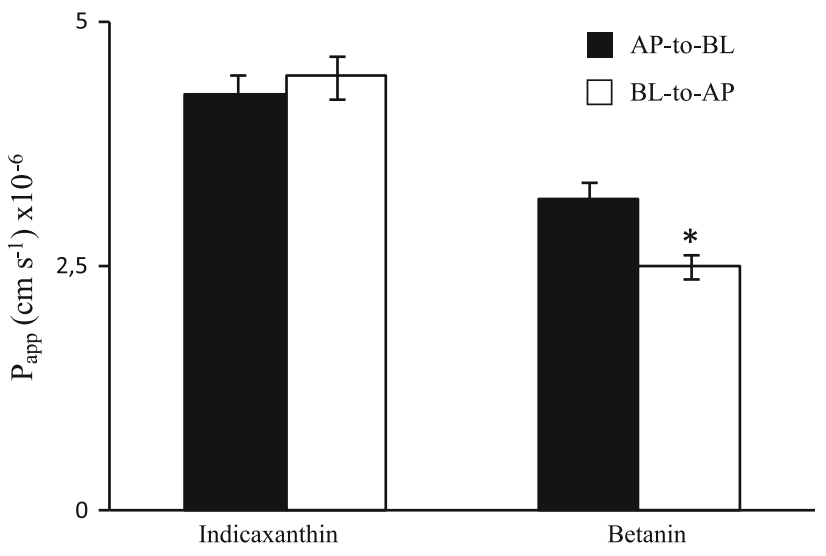

Fig. 2 Bidirectional apparent permeability coefficient $\left(P_{\text {app }}\right)$ of betalains across Caco-2 cell monolayers under inwardly directed $\mathrm{pH}$ gradient (AP pH 6.0/BL pH 7.4). Trans-epithelial transport AP-to-BL (black bars) and BL-to-AP (white bars) and $P_{\text {app }}$ measurements were as reported in Methods. Values are the mean \pm SD of three separate experiments carried out in triplicate. *Statistically significant vs the relevant $P_{\text {app (AP-to-BL) }}$ direction with $p<0.001$ (Student's $t$ test)

recovered in the receiving chamber and the residual compound in the donor one, expressed as percent of the original pigment added. Only traces of the molecules were found in cells. These data indicate that no significant metabolism of betalains had occurred in intestinal cells.

The cumulative amounts of either indicaxanthin or betanin transported into the receiving chamber as a function of time are shown in Fig. 3. The amount of indicaxanthin crossing the monolayer increased linearly with time within $90 \mathrm{~min}$, in both the absorptive and efflux direction, with comparable transport rates (Fig. 3a). For betanin, the relationship was linear in the absorptive direction, whereas a quite different relationship was observed in the efflux transport (Fig. 3b).

In the presence of the proton gradient applied, $\mathrm{H}^{+}$dependent influx carriers were considered. Then, the APto-BL trans-epithelial transport of betanin was measured in the presence of substrates for the monocarboxylate 


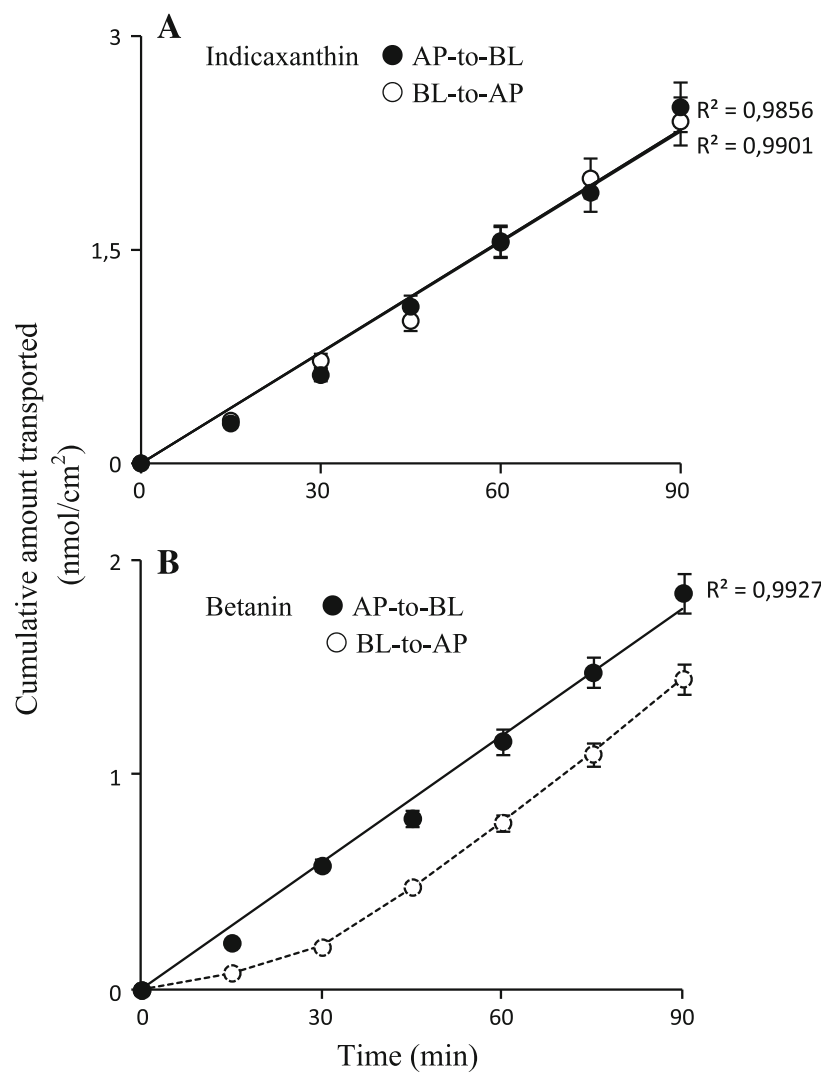

Fig. 3 Kinetics of the bidirectional trans-epithelial transport of indicaxanthin (a) and betanin (b). Measurement conditions were as reported in Methods. Data are the mean $\pm \mathrm{SD}$ of three separate experiments carried out in triplicate. Trend lines (full line) from linear regression analysis fitted through zero showing good linearity $\left(R^{2}>0.95\right)$ are reported

transporter (MCT1) and the organic anion-transporting polypeptide (OATP2B1), as potential competitors. Permeation of betanin was unaffected by either ferulic acid or acetate, both substrates of MCT1 [33, 34], and by pravastatin, a substrate for OATP2B1, whereas valproate, a substrate for both transporters [34], caused an unexpected increase of $P_{\text {app }}$ (Table 2). The AP-to-BL trans-epithelial transport of betanin was also investigated in the presence of either verapamil or indomethacin as specific inhibitors of the efflux proteins P-glycoprotein and multidrug resistance-associated protein 2 (MRP2), respectively [35]. Indomethacin, but not verapamil, caused a significant increase in betanin permeation (Table 2), indicating that absorption of betanin across the cell monolayer was negatively affected by an MRP2-mediated efflux. An inhibition of permeation of around $35 \%$ can be calculated at the applied betanin concentration. As a corollary, these data provided an explanation to the increase of $P_{\text {app }}$ evaluated for betanin in the presence of valproate, since valproate has been shown to be a substrate of MRP2 [36]. Finally, the absorption of glycosylated phytochemicals could involve the $\mathrm{Na}^{+}$-dependent glucose transporter of the brush border
Table 2 Influence of various compounds on the transport rate of betanin across Caco-2 cells monolayers

\begin{tabular}{lcll}
\hline Compound & $\begin{array}{l}\text { Concentration } \\
(\mathrm{mM})\end{array}$ & $\begin{array}{l}P_{\text {app }}(\mathrm{AP}-\mathrm{BL}) \\
\left(\times 10^{-6} \mathrm{cms}^{-1}\right)\end{array}$ & $n$ \\
\hline Control & & $3.21 \pm 0.30$ & 4 \\
Ferulic acid & 10 & $3.17 \pm 0.29$ & 2 \\
Acetic acid & 5 & $3.25 \pm 0.31$ & 2 \\
Pravastatin & 5 & $3.11 \pm 0.35$ & 2 \\
Valproic acid & 10 & $4.51 \pm 0.38^{*}$ & 3 \\
Verapamil & 5 & $3.09 \pm 0.31$ & 2 \\
Indomethacin & 10 & $4.93 \pm 0.33^{*}$ & 3 \\
Glucose & 10 & $3.15 \pm 0.28$ & 2 \\
\hline
\end{tabular}

Betanin $(100 \mu \mathrm{M})$ was added to the apical (AP) compartment of monolayers in the absence (control) or in the presence of each compound at the indicated concentration. Trans-epithelial transport experiments were carried out under gradient $\mathrm{pH}$ conditions $(\mathrm{pH}$ 6.0/ 7.4; AP/BL), at $37{ }^{\circ} \mathrm{C}$, for $60 \mathrm{~min}$ as described in Methods. Data are the mean $\pm \mathrm{SD}$ of $\mathrm{n}$ separate experiments carried out in triplicate. * Statistically significant vs control with $p<0.005$ (Student's $t$ test)

membrane [37]. When $100 \mu \mathrm{M}$ betanin was co-incubated in the apical side with excess glucose, the permeation rate was not significantly modified (Table 2).

In parallel experiments, the AP-to-BL permeability of indicaxanthin was measured in the presence of the mentioned competitors for $\mathrm{H}^{+}$-dependent carriers and efflux transporters, to rule out that the apparent absence of a carrier-mediated transport actually resulted from a false negative. None of the compounds caused variations in the calculated $P_{\text {app }}$ of indicaxanthin (not shown), ruling out the effects of the pigment on the transporters considered.

To further characterize the transfer of betalains, the flux of indicaxanthin and betanin in both directions was evaluated as a function of concentration. The observed relationship was linear for indicaxanthin in both the absorptive and efflux directions (Fig. 4a), in accordance with a simple diffusion process. For betanin, the relationship was linear in the absorptive direction only, which suggested a nonsaturable process, whereas approached saturation was in the BL-to-AP direction (Fig. 4b). The experimental efflux data were then analyzed according to Eq. 2 describing a model consisting of one saturable and one non-saturable term (Fig. 4b, inset). The $J_{\max }$ and $K_{m}$ estimated for the

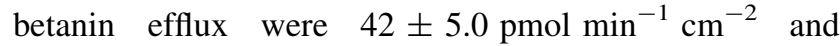
$275 \pm 12 \mu \mathrm{M}$, respectively. The estimated coefficient of non-saturable transport $K_{d}$ was $42 \pm 2 \mathrm{~nL} \mathrm{~min} \mathrm{~cm}^{-1}$. When comparing $K_{d}$ with the saturable transport clearance

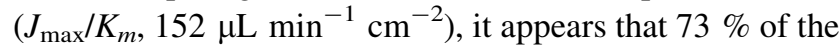
overall betanin efflux occurs via a saturable process, for concentrations $\ll K_{m}$. A comparison of the slopes from the curves representing the non-saturable AP-to-BL and BL-to$\mathrm{AP}$ transports (Fig. $4 \mathrm{~b}$ and inset) indicates that under the 


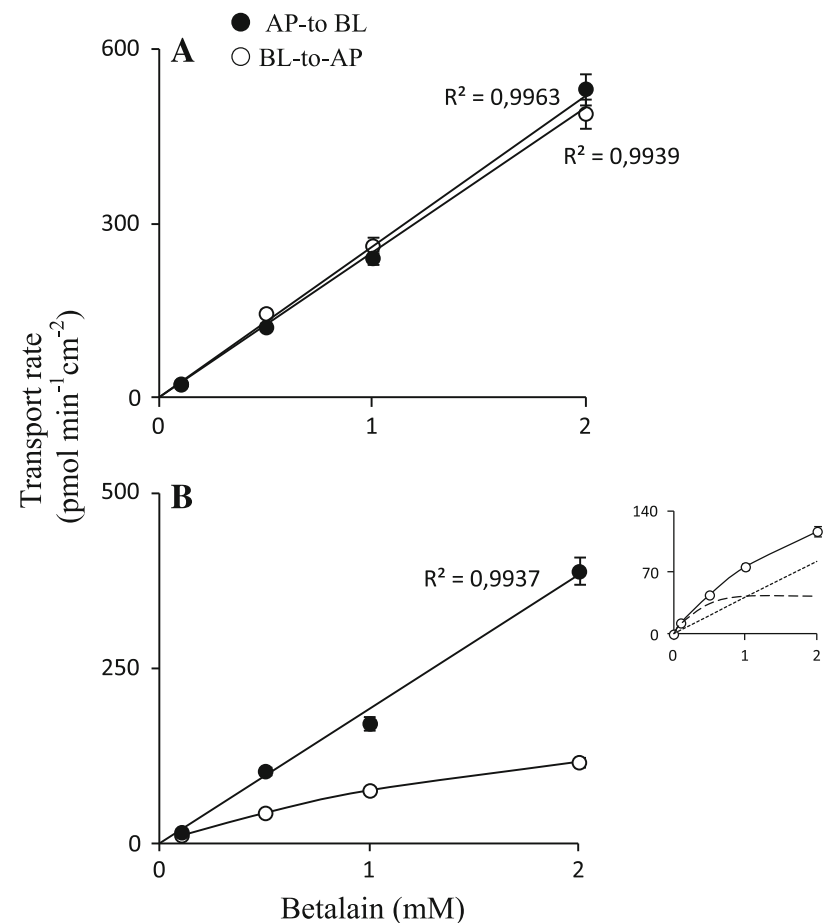

Fig. 4 Concentration-dependent transport of indicaxanthin (a) and betanin (b) across Caco-2 cell monolayers. Measurement conditions are reported in Methods. Data are the mean \pm SD of three separate experiments carried out in triplicate. Trend lines (full line) from linear regression analysis fitted through zero showing good linearity $\left(R^{2}>0.95\right)$ are reported. Inset B: the solid, dashed, and dotted lines represent the best fit to the efflux data, saturable and non-saturable components of the transport, respectively, according to Eq. 2

experimental conditions applied, betanin diffusion is fourfold higher in the influx than in the efflux direction.

The $P_{\text {app }}$ of the AP-to-BL transfer of indicaxanthin and betanin across Caco-2 cell monolayers was evaluated after treatment of the monolayer with EDTA, which affects paracellular permeability via loosening of the tight junctions [31], in comparison with markers for paracellular and transcellular pathways. The $P_{\text {app }}$ value of indicaxanthin increased around 11-fold, and that of betanin sevenfold (Fig. 5). As expected, an effective transfer of phenol red across the epithelial cell layer was observed only after loosening of the TJs, whereas the permeability of testosterone, the transfer of which occurs via a passive trans-cellular pathway, was almost unaffected by the EDTA treatment of the cells (Fig. 5). It was concluded that the transport of both betalains substantially occurred through paracellular permeation.

\section{Transport of betalains from food digesta}

The absorption of betalains from digested betalainic food was evaluated. Cactus pear fresh fruits and juice as a source of indicaxanthin and betanin, as well as raw red beet and red beet juice, as a source of betanin, were processed through a simulated in vitro digestion, and the BFs so obtained were

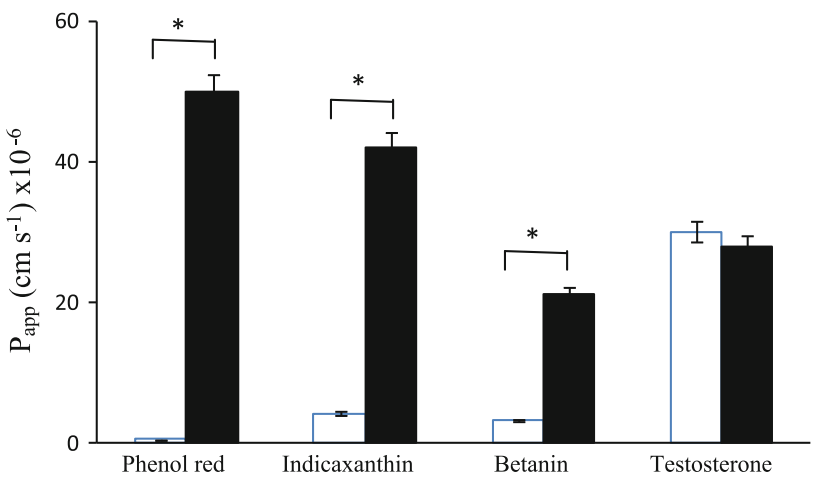

Fig. 5 Apparent permeability coefficient $\left(P_{\text {app }}\right)$ for betalains across Caco-2 cell monolayer with intact tight junctions (open bars) and after opening of tight junctions with $5 \mathrm{mM}$ EDTA (black bars), in comparison with phenol red and testosterone. Data are the mean $\pm \mathrm{SD}$ of two separate experiments carried out in triplicate. *Statistically significant with $p<0.001$ (Student's $t$ test)

Table 3 Apparent permeation coefficient ( $P_{\text {app }}$, AP-BL) across Caco-2 cell monolayers of betalains from the bioaccessible fraction (BF) of betalainic foods

\begin{tabular}{llll}
\hline Betalain & BF source & $\begin{array}{l}\text { Concentration } \\
(\mu \mathrm{M})\end{array}$ & $\begin{array}{l}P_{\mathrm{app}} \\
\left(10^{-6} \mathrm{cms}^{-1}\right)\end{array}$ \\
\hline Indicaxanthin & Cactus yellow fruit & $30.5 \pm 2.3$ & $4.32 \pm 0.35$ \\
& $\begin{array}{l}\text { Cactus yellow fruit } \\
\text { juice }\end{array}$ & $29.8 \pm 3.2$ & $4.15 \pm 0.41$ \\
\multirow{3}{*}{ Betanin } & Raw red beet & $62.5 \pm 5.3$ & $1.98 \pm 0.21^{*}$ \\
& Red beet juice & $11.7 \pm 1.1$ & $1.82 \pm 0.20^{*}$ \\
& Cactus red fruit & $12.2 \pm 1.5$ & $2.78 \pm 0.34^{* *}$ \\
& Cactus red fruit & $13.1 \pm 1.2$ & $2.61 \pm 0.31^{* *}$ \\
& juice & & \\
\hline
\end{tabular}

Preparation of BF from foods and incubation conditions of Caco-2 monolayers were as reported in methods

Values are the mean \pm SD of three determinations carried out on two different food samples. Significantly different from $P_{\text {app }}$ of the relevant pure compound, $* p<0.001, * * p<0.05$ (Student's $t$ test)

placed at the apical side of Caco-2 cells layered on a Transwell insert, after measuring their betalain content. Permeation of indicaxanthin and betanin is reported in Table 3. Whereas permeation of indicaxanthin from cactus pear either fruit or juice was quite comparable with that of the pure pigment, the food matrix reduced the transport rate of betanin, red beet more than cactus pear (Table 3).

\section{Discussion}

Bi-directional transfer of indicaxanthin and betanin through Caco-2 cell monolayers

The intestinal absorption of two bioavailable dietary betalains, betanin and indicaxanthin, has been investigated 
using Caco-2 cell monolayers grown on permeable polyester membranes as a model for the small intestinal mucosal epithelium, and the influence of the betalainic food matrix on the absorption process has been evaluated. Different tracts of the gastro-intestinal lumen are characterized by different $\mathrm{pH}$ values, and further $\mathrm{pH}$ changes are measured during digestion [38]. The $\mathrm{pH}$ in the upper gastro-intestinal tract under fasting conditions ranges from 5.0 to 6.5 , and it has been reported to be 5.8 to 6.3 just above the absorbing epithelial cell layer [39]. We then measured the flux of betalains across the Caco- 2 cell monolayer under conditions of an inwardly directed $\mathrm{pH}$ gradient $\mathrm{pH}$ 6.0/7.4) approaching the $\mathrm{pH}$ microclimate at the luminal and serosal sides of human intestinal cells, with maintaining first-order conditions to mimic physiological absorption circumstances at the small intestine. In addition, the bulk of the experiments were carried out using a $100-\mu \mathrm{M}$ betalain concentration, which approached the amount in the intestinal digesta from dietary amounts of either cactus pear fruit pulp (200 g, $24 \mathrm{mg}$ indicaxanthin) or raw red beet (100 g, $71 \mathrm{mg}$ betanin) [22], when considering an intestinal volume of $600 \mathrm{~mL}$ [40].

Like for xenobiotics, the intestinal absorption of phytochemicals may occur passively, through trans-cellular permeation or paracellular route in accordance with molecular mass and physicochemical characteristics, and could involve either influx or efflux membrane transporters. Our computational analysis provided solubility parameters and the polar and NPSA of indicaxanthin and betanin, as well as dissociation constants of the indicaxanthin carboxyl groups. According to our calculations and literature data $[18,28]$, both compounds mainly occur as bis-anions at $\mathrm{pH}$ 6.0. The octanol/water partition coefficients $C \log P$ and $C \log D$ ( $\mathrm{pH}$ 6.0) indicated that indicaxanthin is moderately less polar than betanin. Finally, the calculated NPSA provided evidence that both betalains have a quite large non-polar surface, accounting for around $50 \%$ of surface area, which substantiated previous observations on the ability of these molecules to interact with lipid environments from membranes [9, 19, 41, 42] to lowdensity lipoproteins $[8,11,17]$.

Generally, unless utilizing transporters in the epithelial membrane, charged solutes of a suitable molecular mass should diffuse through the paracellular route and be transported passively by solvent drag [43-46]. Quite consistent with the physicochemical features of indicaxanthin and betanin, our study shows that both compounds may cross the epithelial cell layer by passive diffusion via the paracellular pathway, without any metabolic transformation. Some findings, however, suggest a mixture of paracellular and trans-cellular transport for betanin.

The effects of perturbation on the permeation of solutes are used as criteria to determine the preferred route of intestinal transport $[32,47]$. If the permeation is significantly affected by perturbation of cellular tight junctions (TJs), then the permeation is considered to occur predominantly by the paracellular route. We observed that an opening of TJs with EDTA induced a remarkable increase in the indicaxanthin and betanin influx, consistent with a paracellular transport of both compounds across the Caco-2 cell monolayer. Indeed, the trans-epithelial transfer of indicaxanthin did not appear to be polarized, did not show saturation kinetics, nor the absorption was varied by inhibiting membrane transporters, in accordance with the simple diffusion-solubility criteria governing paracellular transports. On the other hand, the absorption of the glycosylated betanin appeared polarized, and the cumulative transfer in the efflux direction was not linear with time nor with concentration. Kinetic modeling of the efflux data revealed parallel contribution of one non-saturable and one saturable component, identified as the apical efflux transporter MRP2. Quantitative analysis of the data showed that the betanin efflux mainly occurs through the saturable pathway $(73 \%)$ at betanin concentrations far below $K_{m}$ (i.e. $\ll 275 \mu \mathrm{M}$ ), whereas the betanin diffusion rate is fourfold higher in the influx than in the efflux direction. Then, in spite of the apical efflux, under the present experimental set-up mimicking physiological $\mathrm{pH}$ and betalain concentration conditions, the permeation rate of betanin was higher in the absorptive than in the secretive direction, which should assure that absorption at the intestine will prevail. It may be worthwhile to mention that our experiments have been done with amounts of betalains consistent with the intestinal content after a reasonable dietary intake, which may be critical when dealing with carrier-mediated processes.

The involvement of MRP2 in the transport discloses interesting features of the betanin ability to migrate through the Caco-2 cell monolayer. While indicating that the bioavailability of this phytochemical is limited by an absorption barrier, our findings suggest that trans-cellular transfer of betanin could occur in parallel with the paracellular one. Partition of various ionized species into chemical bilayers has been determined [48], and trans-cellular transport of ionized species across Caco-2 cell monolayers has been suggested in other studies [49, 50]. Moreover, previously performed chemico-physical partition studies in our laboratory provided evidence that betanin locates at the phospholipid core of the bilayer in an aqueous phosphatidylcholine liposomal system [41]. Then, it seems reasonable to suppose betanin permeation of the cell membrane at the apical side, with access to the apical membrane efflux transporter, and possibly lateral diffusion to the basal side of the cell and release to the basolateral compartment.

With solutes of like charge, paracellular permeability is a function of the molecular mass and decreases with the 
increase in molecular weight $[43,44,46]$. Since indicaxanthin and betanin have a comparable ionic charge at $\mathrm{pH}$ 6.0 , the molecular mass should favor the paracellular permeation of indicaxanthin. Noteworthy that in the presence of indomethacin, that is, blocking the MRP2 efflux transporter, the $P_{\text {app }}$ for the absorption of betanin has appeared as high as that of indicaxanthin may be an indirect evidence that additional trans-membrane transport of betanin does occur.

The intestinal absorption of xenobiotics is considered negligible if the $P_{\text {app }}<0.1 \times 10^{-6} \mathrm{~cm} \mathrm{~s}^{-1}$ and essentially complete if the trans-epithelial $P_{\text {app }}>5.0 \times 10^{-6} \mathrm{~cm} \mathrm{~s}^{-1}$ $[51,52]$. With the observed permeability coefficients, the trans-epithelial gradient of indicaxanthin and betanin at the intestinal lumen after ingestion, and their continuous removal by the bloodstream at the serosal side, could account for a significant intestinal transport. Present data indeed are consistent with and appear to validate the high fraction of dietary indicaxanthin absorbed in vivo [17]. Bioavailability of betanin in humans has been shown much lower than that of indicaxanthin [17-19]. According to previous studies [22], around $50 \%$ of betanin is lost during the digestive process; however, its recovery in human urine was found no more than $3 \%$ of the compound ingested with various foods [17-19]. Present findings on the intestinal processing and the calculated $P_{\text {app }}$ do not fully consist with the bioavailability measurements. The complexity of the in vivo system could involve other significant losses, possibly hydrolytic processes by glycosidases of the intestinal microflora, and/or some oxidation of the pigment in the body [12]. Other factors, including the food matrix, could play additional roles.

Influence of betalainic food matrix on the intestinal permeation of the pigments

The absorption efficacy of phytochemicals can be affected by the mixture of their food matrix [53]. With respect to the pure compounds, the trans-epithelial transport rate of betanin from the soluble fraction of betalainic food digesta was strongly reduced, whereas that of indicaxanthin was not. Phenolic groups of phytochemicals may be involved in hydrogen bonding with protein moiety [54], and then complexes between betanin and soluble protein fragments in the post-intestinal digesta could prevent a fraction of the pigment to be absorbed. Eventual competition by other betalainic food components for the paracellular pathway could also be hypothesized. Present observations that betanin from cactus pear appeared more readily absorbed than from red beet are quite in accordance with previous studies in humans, showing higher bioavailability of betanin from dietary cactus pear fruit than from red beet juice [17-19]. This may deserve consideration for nutritional purposes.

\section{Conclusive remarks}

Dietary bioactive phytochemicals are now considered potential nutraceuticals/pharmacological molecules [55], and then analyzing mechanisms and factors affecting intestinal transfer could help to predict their eventual effects in the body. Definite evidence has been provided that the very high bioavailability of dietary indicaxanthin in humans [17] results not only from relatively high stability of the molecule to the digestive process [22], but also from favorable intestinal absorption through paracellular route by solvent drag, and easy release from food. Betanin bioavailability, instead, appears to be limited by digestive instability [22] and by an intestinal efflux mechanism reducing the absorption by around $35 \%$ for betanin concentrations consistent with a nutritional intake. Furthermore, its intestinal permeation may negatively be influenced by its food matrix. Importantly, indicaxanthin and betanin do not need metabolic transformations to be released in plasma and circulate as unconjugated molecules. Taking all these facts into consideration, beneficial effects of dietary betalain pigments, as well as the impact of betalainic foods on human health [56], may be considered and results from appropriately planned in vitro studies may be interpreted to suggest real effects in vivo. Present data may provide a basis for research on the potential health effects of these substances, eventually to be orally administered as purified compounds.

Conflict of interest The authors declare that there are no conflicts of interest.

\section{References}

1. Scalbert A, Johnson IT, Saltmarsch M (2005) Polyphenols: antioxidants and beyond. Am J Clin Nutr 81:215S-217S

2. Raederstorff D (2009) Antioxidant activity of olive polyphenols in humans: a review. Int J Vitam Nutr Res 79:152-165

3. Herr I, Buchler MW (2010) Dietary constituents of broccoli and other cruciferous vegetables: implications for prevention and therapy of cancer. Cancer Treat Rev 36:377-383

4. Piattelli M (1981) The betalains: structure, biosynthesis and chemical taxonomy. In: Conn EE (ed) The biochemistry of plants: a comprehensive treatise, vol 7. Academic Press, New York, pp 557-575

5. Steglich W, Strack D (1990) Betalains. In: Brossi A (ed) The alkaloids, chemistry and pharmacology. Academic Press, London, pp 1-62

6. Herbach KM, Stintzing FC, Carle R (2006) Betalain stability and degradation. Structural and chromatic aspects. J Food Sci 71:R41-R50 
7. Reynoso R, Garcia FA, Morales D, Gonzalez de Mejia E (1997) Stability of betalain pigments from a cactacea fruit. J Agric Food Chem 45:2884-2889

8. Tesoriere L, Butera D, D'Arpa D, Di Gaudio F, Allegra M, Gentile C, Livrea MA (2003) Increased resistance to oxidation of betalain-enriched human low density lipoproteins. Free Radic Res 37:689-696

9. Tesoriere L, Butera D, Allegra M, Fazzari M, Livrea MA (2005) Distribution of betalain pigments in red blood cells after consumption of cactus pear fruits and increased resistance of the cells to ex vivo-induced oxidative hemolysis in humans. J Agric Food Chem 53:1266-1270

10. Tesoriere L, Allegra M, Butera D, Gentile C, Livrea MA (2006) Cytoprotective effects of the antioxidant phytochemical indicaxanthin in beta-thalassemia red blood cells. Free Radic Res 40:753-761

11. Tesoriere L, Allegra M, Butera D, Gentile C, Livrea MA (2007) Kinetics of the lipoperoxyl radical-scavenging activity of indicaxanthin in solution and unilamellar liposomes. Free Radic Res 41:226-233

12. Tesoriere L, Allegra M, Gentile C, Livrea MA (2009) Betacyanins as phenol antioxidants. Chemistry and mechanistic aspects of the lipoproxyl radical scavenging activity in solution and liposomes. Free Radic Res 43:706-717

13. Gentile C, Tesoriere L, Allegra M, Livrea MA, D'Alessio P (2004) Antioxidant betalains from cactus pear (Opuntia ficus indica) inhibit endothelial ICAM-1 expression. Ann NY Acad Sci 1028:481-486

14. Reddy MK, Alexander-Lindo RL, Nair MG (2005) Relative inhibition of lipid peroxidation, cyclooxygenase enzymes, and human tumor cell proliferation by natural food colors. J Agric Food Chem 53:9268-9273

15. Sreekantah D, Arunasree MK, Roy KR, Reddy TC, Reddy GV, Reddanna P (2007) Betanin a betacyanin pigment purified from fruits of Opuntia ficus indica induces apoptosis in human chronic myeloid leukemia cell line-K562. Phytomedicine 14:739-746

16. Kapadia GJ, Azuine MA, Rao GS, Arai T, Iida A, Tokuda H (2011) Cytotoxic effect of the red beetroot (Beta vulgaris, L9 extract compared to doxorubicin (Adriamycin) in the human prostate (PC-3) and breast (MCF-7) cancer cell lines. Anticancer Agents Med Chem 11:280-284

17. Tesoriere L, Allegra M, Butera D, Livrea MA (2004) Absorption, excretion, and distribution in low density lipoproteins of dietary antioxidant betalains. Potential health effects of betalains in humans. Am J Clin Nutr 80:941-945

18. Frank T, Stintzing FC, Carle R, Bitsch I, Quaas D, Strass G, Bitsch R, Netzel M (2005) Urinary pharmacokinetics of betalains following consumption of red beet juice in healthy humans. Pharmacol Res 52:290-297

19. Kanner J, Harel S, Granit R (2001) Betalains-a new class of dietary cationized antioxidants. J Agric Food Chem 49:5178-5185

20. Holt RR, Lazarus SA, Sullards MC, Zhu QY, Schramm DD, Hammrstone JF, Fraga GC, Schmitz HH, Keen C (2002) Procyanidin dimer B2 [epicathechin-(4beta-8)-epicathechin] in human plasma after the consumption of a flavonol-rich cocoa. Am J Clin Nutr 76:798-804

21. Schroeter H, Heiss C, Balzer J, Kleinbongrad P, Keen CL, Hollenberg NK, Sies H, Kwik-Uribe CL, Schmitz HH, Kelm M (2006) (-)-Epicathechin mediates beneficial effects of flavonolrich cocoa on vascular function in humans Proc Nat Acad Sci USA 103:1024-1029

22. Tesoriere L, Fazzari M, Angileri F, Gentile C, Livrea MA (2008) In vitro digestion of betalainic foods. Stability and bioaccessibility of betaxanthins and betacyanins and antioxidative potential of food digesta. J Agric Food Chem 56:10487-10492
23. Galijatovic A, Otake Y, Walle UK, Walle T (2001) Induction of UDP-glucuronyltransferase UGT1A1 by the flavonoid chrysin in Caco2 cells- potential role in carcinogen bioactivation. Pharm Res 18:374-379

24. Sun DX, Lennernas H, Welage LS, Barnett JL, Landowski CP, Foster D, Fleischer D, Lee KD, Amidon JL (2002) Comparison of human duodenum and $\mathrm{Caco} 2$ gene expression profiles for 12,000 gene sequence tags and correlation with permeability of 26 drugs. Pharm Res 19:1400-1416

25. Butera D, Tesoriere L, Di Gaudio F, Bongiorno A, Allegra M, Pintaudi AM, Kohen R, Livrea MA (2002) Antioxidant activities of sicilian prickly pear (Opuntia ficus indica) fruit extracts and reducing properties of its betalains: betanin and indicaxanthin. J Agric Food Chem 50:6895-6901

26. Stintzing FC, Schieber A, Carle R (2002) Identification of betalains from yellow beet (Beta vulgaris, L) and cactus pear (Opuntia ficus indica, L Mill) by high performance liquid chromatography-electrospray ionization mass spectrometry. J Agric Food Chem 50:2302-2307

27. Katritzky AR, Lobanov VS, Karelson M (1996) Quantumchemical descriptors in QSAR/QSPR studies. Chem Rev 96:1027-1043

28. Gliszczynska-Swiglo A, Szymusiak H, Malinowska P (2006) Betanin, the main pigment of red beet: molecular origin of its exceptionally high free radical-scavenging activity. Food Addit Contam 23:1079-1087

29. Hidalgo IJ, Raub TJ, Borchardt RT (1989) Characterization of the human colon carcinoma cell line (Caco-2) as a model system for intestinal epithelial permeability. Gastroenterology 96:736-749

30. Behrens I, Stenberg P, Artusson P, Kissel T (2001) Transport of lipophilic drug molecules in a new mucus-secreting cell culture model based on HT29_MTX cells. Pharmacol Res 18:1138-1145

31. Artursson P (1990) Epithelial transport of drugs in cell culture. I: a model for studying the passive diffusion of drugs over intestinal (Caco-2) absorptive cells. J Pharm Sci 79:476-482

32. Artursson P, Magnusson C (1990) Epithelial transport of drugs in cell culture. II: effect of extracellular calcium concentration on the paracellular transport of drugs of different lipophilicities across monolayers of intestinal epithelial (Caco-2) cells. J Pharm Sci 79:595-600

33. Konishi Y, Shimizu M (2003) Transepithelial transport of ferulic acid by monocarboxylic acid transporter in Caco-2 cell monolayers. Biosci Biotechnol Biochem 67:856-862

34. Thwaites DT, Anderson CMH (2007) H + -coupled nutrient, micronutrient and drug transporters in the mammalian small intestine. Exp Physiol 92:603-619

35. Shugarts S, Benet LZ (2009) The role of transporters in the pharmacokinetics of orally administered drugs. Pharm Res 26:2039-2045

36. Ogawa K, Yumoto R, Hamada N, Nagai J, Takano M (2006) Interaction of valproic acid and carbapenem antibiotics with multidrug resistance-associated proteins in rat erythrocyte membranes. Epilepsy Res 71:76-87

37. Walgren RA, Lin J-T, Kinne RK-H, Walle T (2000) Cellular uptake of dietary flavonoid quercetin $44^{\prime}-\beta$-glucoside by sodiumdependent glucose transporter SLGT1. J Pharmacol Experim Therap 294:837-843

38. Dressman JB, Berardi RR, Dermentzoglou LC, Russel TL, Schmaltz SP, Barnett JL, Jarvenpaa KM (1990) Upper gastrointestinal (GI) $\mathrm{pH}$ in young, healthy men and women. Pharm Res 7:756-761

39. Lucas M (1983) Determination of acid surface $\mathrm{pH}$ in vivo in rat proximal jejunum. Gut 24:734-739

40. Mahe S, Huneau JF, Marteau P, Thuillier F, Tome D (1992) Gastroileal nitrogen and humans. Am J Clin Nutr 56:410-416 
41. Turco Liveri ML, Sciascia L, Lombardo R, Tesoriere L, Passante E, Livrea MA (2007) Spectrophotometric evidence for the solubilization site of betalain pigments in membrane biomimetic systems. J Agric Food Chem 55:2836-2840

42. Turco Liveri ML, Sciascia L, Allegra M, Tesoriere L, Livrea MA (2009) Partition of indicaxanthin in membrane biomimetic systems. A kinetic and modeling approach. J Agric Food Chem 57:10959-10963

43. Adson A, Raub TJ, Burton PS, Barshun CL, Hilgers AR, Audus KL, Ho NF (1994) Quantitative approach to delineate paracellular diffusion in cultured epithelial cell monolayer. J Pharm Sci 83:1529-1536

44. Karlsson J, Ungell AL, Artursson P (1994) Effect of an oral rehydration solution on paracellular drug transport in intestinal epithelial cells and tissues: assessment of charge and tissue selectivity. Pharm Res 11:S248

45. Pade V, Stavchansky S (1997) Estimation of the relative contribution of the transcellular and paracellular pathway to the transport of passively absorbed drugs in the Caco- 2 cell culture model. Pharm Res 14:1210-1215

46. Knipp GT, Ho NF, Barsuhn CL, Borchardt R (1997) Paracellular diffusion in Caco-2 cell monolayers: effect of perturbation on the transport of hydrophilic compounds that vary in charge and size. J Pharm Sci 86:1105-1110

47. Gan LS, Hsyu PH, Pritchard JF, Thakker D (1993) Mechanism of intestinal absorption of ranitidine and ondansetron: transport across Caco-2 cell monolayer. Pharm Res 10:1722-1725

48. Avdeef A, Box KJ, Comer JEA, Hibbert C, Tam KY (1998) pHmetric $\log \mathrm{P} 10$. Determination of liposomal membrane-water partition coefficients of ionizable drugs. Pharm Res 15:209-215
49. Palm K, Luthman K, Ros J, Grasjo J, Artursson P (1999) Effect of molecular charge on intestinal epithelial drug transport: $\mathrm{pH}$ dependent transport of cationic drugs. J Pharmacol Exp Ther 291:435-443

50. Menez C, Buyse M, Dugave C, Farinotti R, Barratt G (2007) Intestinal absorption of miltefosine: contribution of passive paracellular transport. Pharm Res 24:546-554

51. Hillgren KM, Kato A, Borchardt RT (1995) In vitro systems for studying intestinal drug absorption. Med Res Rev 15:83-109

52. Artursson P, Karlsson J (1991) Correlation between oral drug absorption in humans and apparent drug permeability coefficients in human intestinal epithelial (Caco-2) cells. Biochem Biophys Res Commun 175:880-885

53. Boyer J, Brown D, Liu RH (2004) Uptake of quercetin 3-glucoside from whole onion and apple peel extracts by Caco-2 cell monolayers. J Agric Food Chem 52:7172-7179

54. Hagerman AE, Butler LG (1981) The specificity of proanthocyanidin-protein interactions. J Biol Chem 256:4494-4497

55. Konishi T (2011) From herb to kitchen and bedside: food factors are pharmacological molecules with antioxidant activity. Free Radic Res 45:863-864

56. Tesoriere L, Butera D, Pintaudi AM, Allegra M, Livrea MA (2004) Supplementation with cactus pear (Opuntia ficus-indica) fruit decreases oxidative stress in healthy humans: a comparative study with vitamin C. Am J Clin Nutr 80:391-395 